\title{
Whole genome sequencing of four bacterial strains from South Shetland Trench revealing biosynthetic and environmental adaptation gene clusters
}

\author{
Wael M. Abdel-Mageed ${ }^{\mathrm{a}, \mathrm{b}, *}$, Burhan Lehri ${ }^{\mathrm{c}}$, Scott A. Jarmusch ${ }^{\mathrm{d}}$, Kevin Miranda ${ }^{\mathrm{d}}$, Lamya H. Al-Wahaibi ${ }^{\mathrm{e}}$, \\ Heather A. Stewart ${ }^{\mathrm{f}}$, Alan J. Jamieson ${ }^{\mathrm{g}}$, Marcel Jaspars ${ }^{\mathrm{d}, *}$, Andrey V. Karlyshev ${ }^{\mathrm{c}}$
}

${ }^{a}$ Department of Pharmacognosy, College of Pharmacy, King Saud University, P.O. Box 2457, Riyadh 11451, Saudi Arabia.

${ }^{\mathrm{b}}$ Department of Pharmacognosy, Faculty of Pharmacy, Assiut University, Assiut 71526, Egypt.

${ }^{c}$ School of Life Sciences Pharmacy and Chemistry, Faculty of Science, Engineering and Computing, Kingston University, Kingston upon Thames, Penrhyn Road, KT1 2EE, UK.

${ }^{\mathrm{d}}$ Marine Biodiscovery Centre, Department of Chemistry, University of Aberdeen, Old Aberdeen, Scotland, AB24 3UE, $U K$.

${ }^{\mathrm{e}}$ Department of Chemistry, Science College, Princess Nourah Bint Abdulrahman University, Riyadh 11671, Saudi Arabia.

${ }^{\mathrm{f}}$ British Geological Survey, Lyell Centre, Research Avenue South, Edinburgh, EH14 4AP, UK.

${ }^{\mathrm{g}}$ School of Natural and Environmental Sciences, Newcastle University, Newcastle Upon Tyne, NE1 7RU, UK.

\section{* Corresponding authors}

E-mail address: wabdelmageed@ksu.edu.sa (W. Abdel-Mageed); m.jaspars@abdn.ac.uk (M. Jaspars) 


\section{ABSTRACT}

Whole genome sequences of four bacterial strains Dietzia maris SST1, Pseudomonas zhaodongensis SST2, Pseudomonas sp. SST3 and Halomonas sulfidaeris SST4, recovered from the South Shetland Trench sediment in Antarctica were analyzed using Ion Torrent sequencing technology. The respective sizes of their genomes $(3.88,4.99,5.60$ and $4.25 \mathrm{Mb})$ and $\mathrm{GC}$ contents $(70.0,60.3,59.9$ and $53.8 \%)$ are in agreement with these values of other strains of the species. The bacterial strains displayed promising antimicrobial activity against a number of pathogenic bacterial and fungal species. Whole genomes have been assembled and biosynthetic gene clusters (BGCs) have been identified using the antibiotics and Secondary Metabolite Analysis Shell (antiSMASH) web platform. Comparative analysis of the genome sequences revealed that the strains host abundant BGCs encoding for terpenes, siderophores, arylpolyene, bacteriocins, and lassopeptides. Furthermore, the key stress-related genes were identified and their distribution provided an insight into how these isolates adapt to key marine environmental conditions. This comprehensive study is a contribution to understanding the nature of life on the deepsea environments.

\section{Keywords}

South Shetland Trench, Dietzia sp., Pseudomonas sp., Halomonas sp., Genome sequencing, Biosynthetic gene clusters, antimicrobials. 


\section{Introduction}

The deep-sea environment is of particular interest for drug discovery because it is a relatively unexplored area due to the difficulty in accessing it. Recent technological advances assisted exploration of life in this extreme environment and led to the identification of novel microorganisms with unexplored chemical and biological diversity, possibly leading to the discovery of new bioactive chemistry (Skropeta, 2008; Abdel-Mageed et al., 2010; Skropeta and Wei, 2014; Wagner et al., 2014; Kamjam et al., 2017).

The South Shetland Trench (SST) is the subduction zone located along the western Pacific margin of the Antarctic Peninsula, northwest of the South Shetland Islands. The SST lies within a zone dominated by sedimentation of terrigenous mud and shows evidence of the input of ice-rafted debris and glaciers. The SST is undoubtedly host a number of unique extremophilic and/or polyextremophilic micro- and macro-organisms. The deepest point of the trench is reported to be $5200 \mathrm{~m}$, and the temperature near the seafloor at the deepest area will decrease to near $0{ }^{\circ} \mathrm{C}$, where pressures exceed $52 \mathrm{MPa}$ (Jin et al., 2009). Due to their unique properties, deep-sea microorganisms are considered as invaluable resources for exploration of biological and chemical diversity of life, and for drug discovery.

This study was designed to establish the taxonomic status and explore the genetic features of four unique marine bacterial isolates, SST1, SST2, SST3 and SST4, recovered from the South Shetland Trench sediment as shown in Table 1, for providing insights into their chemical potential as well as the adaptation to the cold and high pressure stress conditions. To our knowledge, this is the first genomic analysis of bacterial isolates from the SST sediments focusing on the biosynthetic gene clusters and marine adaptation. 


\section{Materials and methods}

\subsection{Ethics Statement}

The collection of the marine microbes from the deep the South Shetland Trough was approved by Foreign and Common wealth office. The permit (No. 51/2015 and 52/2015) granted under Section 3, Section 6 and Section 7 of the Antarctic Act 1994 to Alan J. Jamieson (the permit holder) on behalf of the University of Aberdeen, 13 Eilean Rise, Ellon, Aberdeenshire, Scotland AB41 9NF. The main purpose of the permit is to collect the marine organisms from deep and cold habitats (2000m to $5500 \mathrm{~m}$ ) to perform the first marine biological survey of the South Shetland Trough and compare and contrast the fauna with other trench ecosystems.

\subsection{Sample collection}

The strains were recovered from sediment collected from a South Shetland Trench (SST) region at depth ranged from 1950 - 5200 m by scientists from four European countries (UK, Spain, Italy, and Poland) using the Spanish Antarctic Vessel BIO Hesperides during the 'PharmaDEEP' cruise. The samples were collected in a period from $20^{\text {th }}$ until $26^{\text {th }}$ of December, 2015. During this period, six baited landers (with trap and Conductivity Temperature and Depth (CTD) sensor), eight gravity cores, two multi-cores, three beam trawls, thirty-eight zooplankton hauls and nineteen phytoplankton hauls were conducted. Considerable areas of trench were surveyed using a multi-beam echo sounder and subbottom profiler. Four sediment samples were collected at depth 1950, 4160, 5100, and $5194 \mathrm{~m}$.

\subsection{Strain isolation and culturing conditions}

Strain SST1 was isolated from a sediment sample collected from the South Shetland Trench, Antarctica (-58.035554, -61.304726) at a water depth of $1950.2 \mathrm{~m}$. Strains SST2, SST3, and SST4 were 
isolated from a sediment sample collected from South Shetland Trench, Antarctica (-58.2633672, 60.9820589 ) at a water depth of $5194.1 \mathrm{~m}$ (Table 1). One gram of sediment was suspended in $2 \mathrm{~mL}$ of sterile purified water for 24 hours. Subsequently $5 \mu \mathrm{L}$ of each soil suspension were inoculated on 3 media types in triplicate: ISP2 (4 g/L yeast extract, $4 \mathrm{~g} / \mathrm{L}$ glucose, $10 \mathrm{~g} / \mathrm{L}$ malt extract, $20 \mathrm{~g} / \mathrm{L}$ agar); R2A (Reasoner's 2A agar) $(18.2 \mathrm{~g} / \mathrm{L})+$ cycloheximide $\left(50 \mathrm{~g} \mathrm{~L}^{-1}\right)$; and Marine Agar $(37.4 \mathrm{~g} / \mathrm{L}$ broth, 20 $\mathrm{g} / \mathrm{L}$ ). Plates were incubated at $10{ }^{\circ} \mathrm{C}$ for a period of $20-40$ days. Colonies were then successively isolated, inoculated, and incubated until pure cultures were obtained. Strain SST1 was isolated on ISP2, SST2 on R-2A + cycloheximide, SST3 and SST4 on Marine Agar. The cultures were suspended in aqueous glycerol $(20 \%, \mathrm{v} / \mathrm{v})$ at $-80{ }^{\circ} \mathrm{C}$ for storage. All ISP2 components, R-2A, and agar (were purchased from Sigma-Aldrich. Marine broth was purchased from Difco.

Table 1. General information for samples collections and strains isolation.

\begin{tabular}{|c|c|c|c|c|c|c|}
\hline Strain & Sample Name & Date & $\begin{array}{l}\text { Latitude } \\
\text { (West) }\end{array}$ & $\begin{array}{l}\text { Longitude } \\
\text { (South) }\end{array}$ & $\begin{array}{l}\text { Water Depth } \\
(\mathrm{m})\end{array}$ & Media \\
\hline Dietzia maris SST1 & PD_GC_01_01 & $20 / 12 / 2015$ & -58.03555 & -61.304726 & 1950.2 & ISP2 \\
\hline $\begin{array}{l}\text { Pseudomonas zhaodongensis } \\
\text { SST2 }\end{array}$ & PD_GC_0X_06 & $23 / 12 / 2015$ & -58.26336 & -60.982058 & 5194.1 & $\begin{array}{l}\mathrm{R}-2 \mathrm{~A} / \\
\text { cycloheximide }\end{array}$ \\
\hline Pseudomonas sp. SST3 & PD_GC_0X_06 & $23 / 12 / 2015$ & -58.26336 & -60.982058 & 5194.1 & MB \\
\hline Halomonas sulfidaeris SST4 & PD_GC_0X_06 & $23 / 12 / 2015$ & -58.26336 & -60.982058 & 5194.1 & MB \\
\hline
\end{tabular}

\subsection{Characterization of isolates}

\subsubsection{Phenotypic Characterization}

The morphological characteristics of colonies such as shape, color and opacity were studied. In addition, the samples were investigated using Gram staining. All descriptions of morphology fall in line with the standard procedures laid out by the American Society for Microbiologists (Donald et al., 2013). 


\subsubsection{Scanning Electron Microscopy (SEM)}

Each agar plate with culture was fixed by flooding the plate with $2.5 \%$ glutaraldehyde in $0.1 \mathrm{M}$ phosphate buffer $\mathrm{pH} 7.2$ for 12 hours at $4{ }^{\circ} \mathrm{C}$. The sample was successively washed with buffer $(2 \times 5$ min), flooded with $1 \%$ osmium in distilled water $(1 \mathrm{hr})$, washed $(3 \times 5 \mathrm{~min})$ with buffer, then washed 10 min each with $70 \%, 80 \%$, and $90 \%$ ethanol, and lastly washed with $100 \%$ ethanol $(3 \times 10 \mathrm{~min})$. Samples were then dried using Critical Point Drying (CPD) using a BAL-TEC CPD 030 and mounted on $12 \mathrm{~mm}$ aluminum pin stubs with araldite and coated with Au-Pd. All SEM was completed using Carl Zeiss Gemini SEM 300 and all data analysis was completed with Oxford Instruments AZtec Energy and AZtec HKL software suites.

\subsection{DNA extraction}

Genomic DNA (gDNA) was extracted using DNeasy Ultraclean Microbial Kit (Qiagen). Liquid media cultures for bacterial DNA extraction were performed in appropriate media at $20{ }^{\circ} \mathrm{C}, 150 \mathrm{rpm}$ for $4-7$ days. The gDNA extraction was completed following the protocol provided in the kit.

\subsection{Small Scale Fermentation and Extraction}

Small-scale cultures $(50 \mathrm{~mL}$ ) for biological and chemical analysis were grown in ISP2 (SST2 and SST3) and Marine broth (SST4) at $20{ }^{\circ} \mathrm{C}, 150 \mathrm{rpm}$ for 14 days. Diaion HP-20 resin $\left(60 \mathrm{~g} \mathrm{~L}^{-1}\right)$ was added to liquid cultures on day 13 of culturing. HP-20 and liquid media were subjected to Büchner funnel filtration. HP-20 was then washed with $3 \times$ Milli-Q water (Barnstead Diamond RO) and extracted with 3 $\times$ methanol. Crude extracts of strains SST2 and SST3 were then submitted for biological screening. Strain SST4 underwent liquid-liquid partition via modified Kupchan methodology (Kupchan et al., 1973) Each fraction of SST4 was then sent for biological screening. Methanol was purchased from Honeywell Research Chemicals, UK. 


\subsection{Genome sequencing information}

\subsubsection{Genome sequencing}

The sequencing library was prepared using NEBNext Fast DNA Fragmentation and Library Preparation Kit for Ion Torrent (New England Biolabs) according to the manufacturer's protocol. Briefly, $0.5 \mu \mathrm{g}$ of each DNA was subjected to enzymatic fragmentation, end repair and ligation to A1 and P2 adapters. The A1 adapters were barcoded via incorporation of short nucleotide sequences to allow running several genome sequencing samples on the same chip. The adapter-ligated fragments were run on E-gel for selection of fragments of about $500 \mathrm{bp}$, followed by PCR and the analysis of the library quality and estimation of DNA concentrations using High Sensitivity DNA kit and the BioAnalyser 2100 (Agilent). AMPure XP beads (Beckman Coulter) were used for DNA purification according to protocol. After appropriate dilution of libraries to achieve the final combined concentration

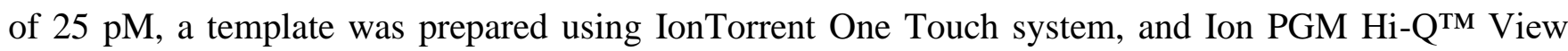
OT2 Kit. Following the template preparation reaction, positive Ion Sphere Particles were recovered using One Touch ES enrichment system. The IonTorrent sequencing was performed using 316v2 chips and Ion PGM Hi-Q ${ }^{\mathrm{TM}}$ View Sequencing Kit with 850 sequencing flows required for $400 \mathrm{nt}$ read length.

\subsubsection{Genome annotation and bioinformatics analysis}

The sequencing reads were mapped onto reference genome sequences using CLC Genomics Workbench software (GWB, ver. 7.5). The assembly of reads was carried out using Torrent MIRA v. 4.0.2.1, SPAdes v. 3.1.0 plugin and CLC Genomics Workbench de novo assembly programs. The annotation of the genomic sequences was conducted using NCBI GenBank annotation pipeline (Altschul et al., 1990) and RAST (Rapid Annotation using Subsystem Technology) (Aziz et al., 2008) tools.

\subsubsection{Taxonomic analysis}


Read mapping onto reference genome sequences using CLC GWB allowed the extraction of complete16S rRNA gene sequences, which were analyzed by using NCBI BLASTN on-line server and the integrated database EzBioCloud (Yoon et al., 2017) for strain identification at the genus and species levels.

\subsubsection{Phylogenetic Analyses}

Phylogenetic trees for the isolates based on high quality 16S rRNA sequences, closely related isolates were obtained by EzBioCloud 16S database (Yoon et al., 2017), only 16S rRNA sequences with valid names were selected. The phylogenetic trees were built with MEGA7 (Kumar et al., 2016) using Maximum Likelihood based on Tamura-Nei model (Tamura and Nei, 1993). Bootstrap test was conducted with 500 replicates (Felsenstein, 1985). Rhodococcus rhodochruos was used as an outgroup for Dietzia maris SST1, Acinetobacter calcoaceticus was used as an outgroup for Pseudomonas zhaodongensis SST2 and Pseudomonas sp. SST3 whilst Chromohalobacter marismortui was used as an outgroup for Halomonas sulfidaeris SST4.

\subsubsection{Detection of the gene clusters}

AntiSMASH 4.0 (Weber et al., 2015) was used to mine the whole genome for annotation of biosynthetic gene clusters, while NCBI GenBank annotation pipeline and RAST were used for detection of different proteins and genes responsible for adaptation.

\subsection{Biological screening}

All biological screening was carried out at Fundación MEDINA. Antimicrobial screenings were performed with extract concentration of $300 \mu \mathrm{g} / \mathrm{mL}$ (SST2) and $100 \mu \mathrm{g} / \mathrm{mL}$ (SST3 and SST4) on 
Escherichia coli ATCC25922, Acinetobacter baumannii MB5973, methicillin-resistant Staphylococcus aureus MB5393, Candida albicans ATCC 64124, Aspergillus fumigatus ATCC 46645. All MTT cytotoxicity assays were performed with extract concentration of $75 \mathrm{mM}$ on the hepatic cell line Hep-G2 (Cautain et al., 2015).

\subsection{Molecular Networking}

High resolution tandem mass spectrometry (HR-MS/MS) data for the four SST strains was generated using Agilent 1290 Infinity UHPLC coupled to a Bruker MAXIS II Q-ToF mass spectrometer. LC separations utilized a Phenomenex Kinetex XB-C18 $(2.6 \mu \mathrm{M}, 100 \times 2.1 \mathrm{~mm})$ column. MS and MS2 experiments were carried out in positive ionization modes using a MS and MS2 range of m/z 100-2000. HR-MS/MS raw data files were converted from .baf to .mzXML using MSConvert and a molecular network was created using Global Natural Products Social (GNPS) Molecular Networking (Wang et al., 2016). GNPS parameters for creating the molecular network were not changed from the standard parameters GNPS recommends except for the minimum peak intensity, which was set to $5 \%$ in order to remove any potential artifacts from interfering in the analysis.

\section{Results and discussion}

In this study we sequenced, annotated and analyzed genomes of four different marine bacterial isolates recovered from the South Shetland Trench (SST) sediment to highlight their chemical potential as well as their adaptation to the deep sea stress conditions. This is considered the first record focusing on the genomic analysis of bacterial isolates from SST sediments to explore their genetic features, biosynthetic gene clusters and deep sea adaptations.

\subsection{Genome sequencing and annotation}


The result of genome assembly of the sequences performed by the Torrent MIRA and SPAdes plugin is shown in Table 2. The annotation of the genomic sequences was performed using NCBI GenBank annotation pipeline and RAST tool (Altschul et al., 1990; Aziz et al., 2008). The assembly sizes, $\mathrm{G}+\mathrm{C}$ contents are in a good agreement with these values for the genomes of other strains of these species available at NCBI GenBank.

Table 2. General features of the genomes of SST species.

\begin{tabular}{lllll}
\hline Attribute & SST1 & SST2 & SST3 & SST4 \\
\hline Assembly Size & $3,878,545$ & $4,989,439$ & $5,601,070$ & $4,254,519$ \\
Number of contigs & 152 & 48 & 245 & 49 \\
G+C & $70 \%$ & $60.3 \%$ & $59.9 \%$ & $53.8 \%$ \\
Genome coverage & $43.41 \times$ & $57.34 \times$ & $55.35 \times$ & $124.31 \times$ \\
N50 & 65,154 & 228,458 & 203,426 & 242,485 \\
L50 & 20 & 7 & 11 & 5 \\
No. RNAs & 55 & 55 & 84 & 66 \\
(rRNA + tRNA) & & & & QNTU00000000 \\
Accession No. & QNTT00000000 & QNTV00000000 & QORI02000000 & QN \\
Assembly method & SPAdes v. 3.1.0 & SPAdes v. 3.1.0 & MIRA v. 4.0.2.1 & SPAdes v. 3.1.0 \\
\hline
\end{tabular}

The Whole Genome Shotgun projects have been deposited at DDBJ/ENA/GenBank under the accession numbers QNTT00000000 (SST1), QNTV00000000 (SST2), QORI02000000 (SST3) and QNTU00000000 (SST4). The versions described in this paper are QNTT01000000 (SST1), QNTV01000000 (SST2), QORI02000000 (SST3) and QNTU01000000 (SST4).

\subsection{Taxonomy, Phylogeny and Features}

Based on 16S rRNA sequence similarity, SST1 was identified as Dietzia maris, SST2 as Pseudomonas zhaodongensis, SST3 as Pseudomonas sp., and SST4 as Halomonas sulfidaeris. The 
bootstrap values (Fig. 1) infer good statistical significance for the taxonomical positioning of the aforementioned organisms, although there is weak statistical significance for the positioning of other organisms placed within the tree. Early branching of the sequenced bacteria (Fig. 1) may be due to the limited data available for samples obtained from the South Shetland deep sea environment.

Dietzia maris strain SST1 (family Dietziaceae, order Actinomycetales), is a Gram-positive cocci growing occasionally as short rods of $1-2 \mu \mathrm{m}$ long and $0.4-1 \mu \mathrm{m}$ wide with aerobic metabolism and are non-spore forming (Table 3, Fig. 2a). The colony is circular convex or raised deep orange colony after growth on ISP2 media for 5 days at $25^{\circ} \mathrm{C}$.

Pseudomonas zhaodongensis SST2 and Pseudomonas sp. SST3 (family Pseudomonadaceae, class Gammaproteobacteria), are Gram-negative, facultatively anerobic, straight to slightly curved rods, 1.7 $2.2 \mu \mathrm{m}$ long and $0.5-0.9 \mu \mathrm{m}$ wide, motile with peritrichous flagella (Table 3, Fig. 2b \& 2c). Colonies are light yellow, round, smooth, convex and translucent grown on R-2A at $15{ }^{\circ} \mathrm{C}$ for 2 to 3 weeks (SST2) and ISP2 at $25^{\circ} \mathrm{C}$ for 5 days (SST3).

Halomonas sulfidaeris SST4 (family Halomonadaceae, class Gammaproteobacteria), is a Gramnegative, facultative aerobic, rods with rounded ends, $2.0-3.5 \mu \mathrm{m}$ long and $0.5-1.0 \mu \mathrm{m}$ wide, motile with peritrichous flagella and non-spore forming (Table 3, Fig. 2d). The colonies are smooth, circular, convex, and white-creamy in color after incubation on marine agar media for 5 days at $25{ }^{\circ} \mathrm{C}$. 


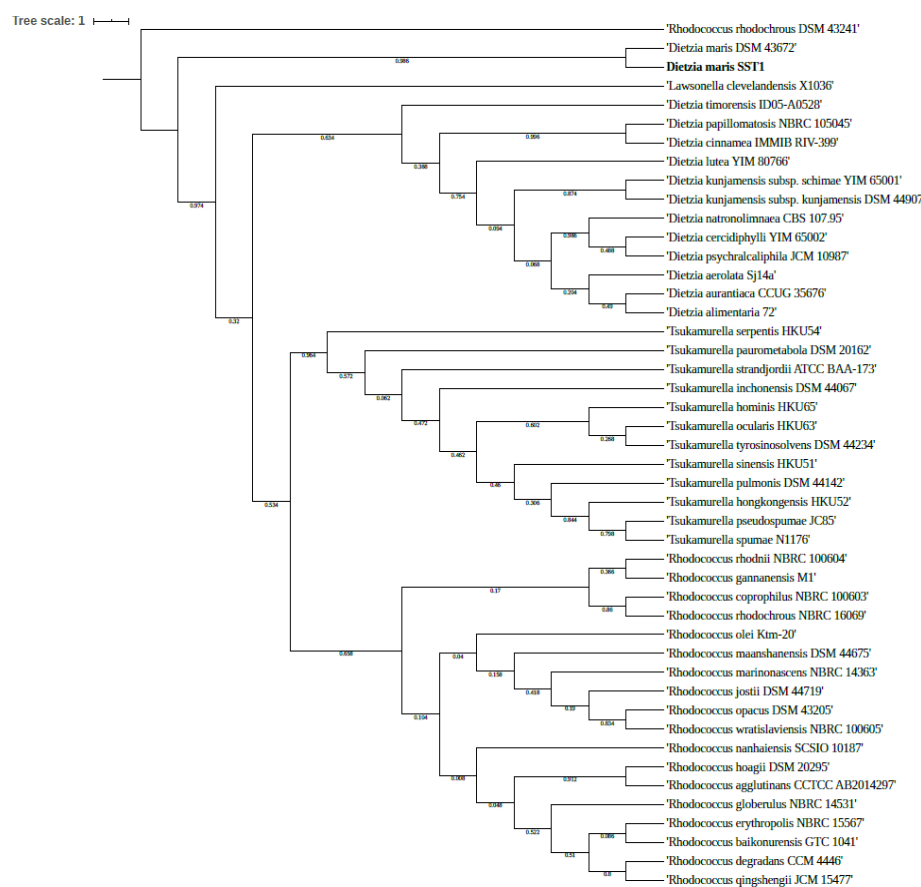

$\mathbf{a}$

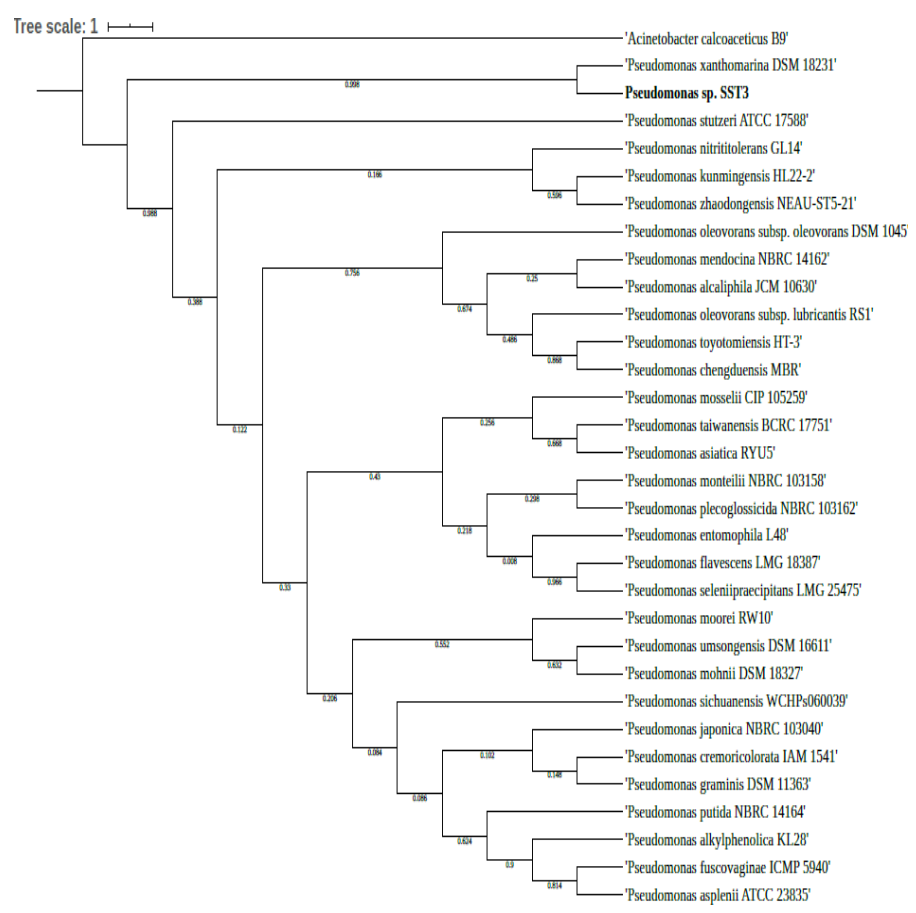

c

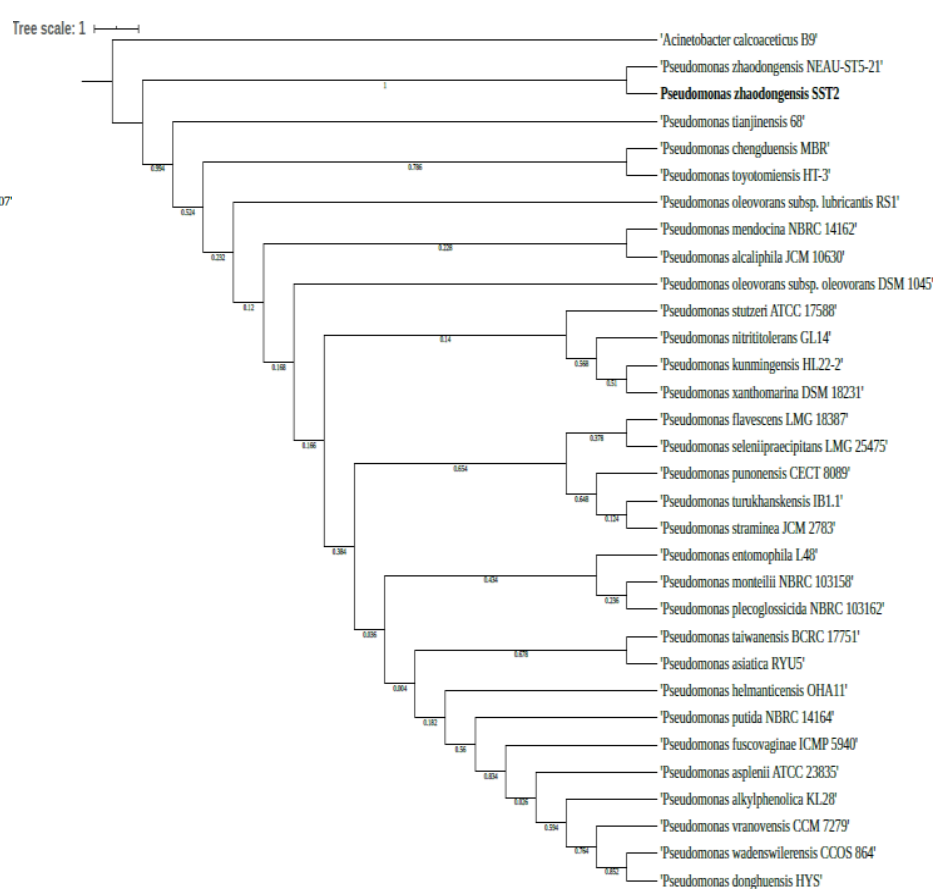

b

Tree scale: 1 1

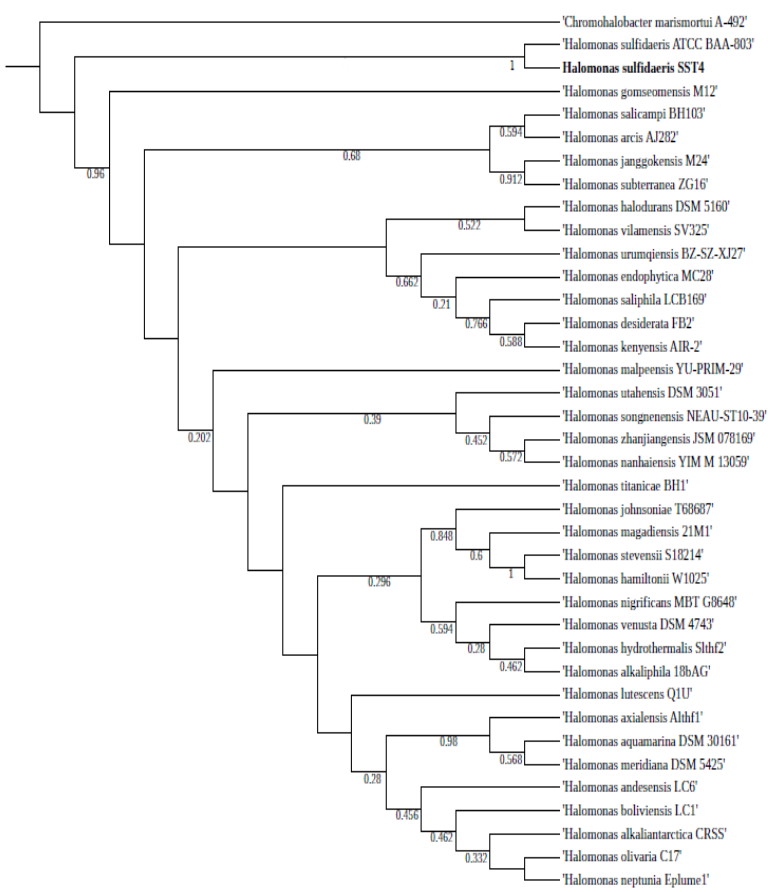

d

Fig. 1. Phylogenetic trees for a) Dietzia maris SST1, b) Pseudomonas zhaodongensis SST2, c) Pseudomonas sp. SST3, d) Halomonas sulfidaeris SST4 based on high quality 16S rRNA sequences obtained by using the EzBioCloud 16S database. The phylogenetic tree was built using Maximum Likelihood Tamura-Nei model, by using MEGA7, visualized using Interactive Tree Of Life (ITOL) (Letunic and Bork, 2019). 
Table 3. Classification and general features of SST species.

\begin{tabular}{lllll}
\hline Property & SST1 & SST2 & SST3 & SST4 \\
\hline Classification & Phylum: Actinobacteria & Phylum: Proteobacteria & Phylum: Proteobacteria & Phylum: Proteobacteria \\
& Class: Actinobacteria & Class: Gammaproteobacteria & Class: Gammaproteobacteria & Class: Gammaproteobacteria \\
& Order: Actinomycetales & Order: Pseudomonadales & Order: Pseudomonadales & Order: Oceanospirillales \\
& Family: Dietziaceae & Family: Pseudomonadaceae & Family: Pseudomonadaceae & Family: Halomonadaceae \\
& Genus: Dietzia & Genus: Pseudomonas & Genus: Pseudomonas & Genus: Halomonas \\
& Species: maris & Species: zhaodongensis & Species: unknown & Species: sulfidaeris \\
Gram Stain & Positive & Negative & Negative & Negative \\
Cell Shape & Short rods & Rod & Rod & Rod \\
color & Orange red & Translucent & Translucent & white/yellow \\
Growth Media & ISP2 agar & R-2A agar & ISP2 agar & Marine agar \\
Temperature & $25^{\circ} \mathrm{C}$ & $15^{\circ} \mathrm{C}$ & $25^{\circ} \mathrm{C}$ & $25^{\circ} \mathrm{C}$ \\
Period & 5 days & $14-20$ days & 5 days & 5 days \\
\hline
\end{tabular}

a

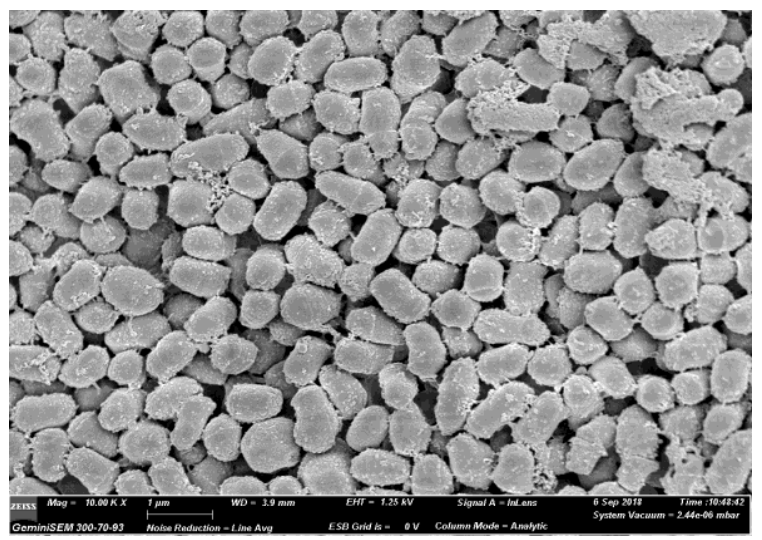

b

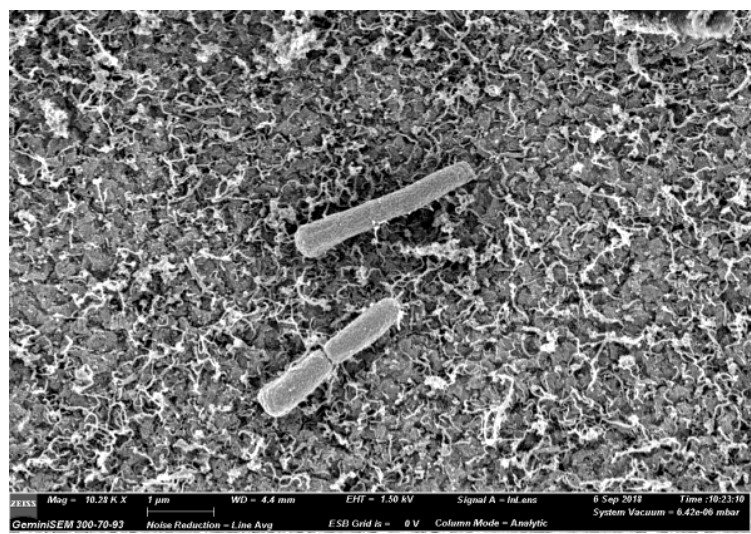

c

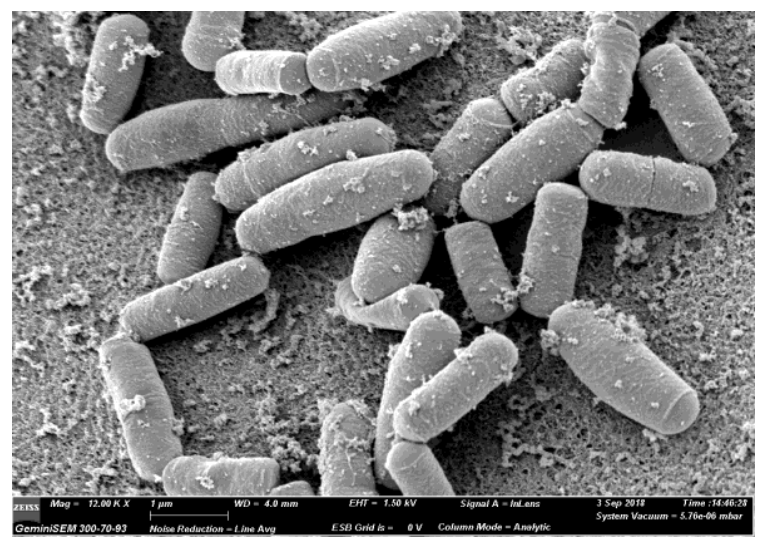

d

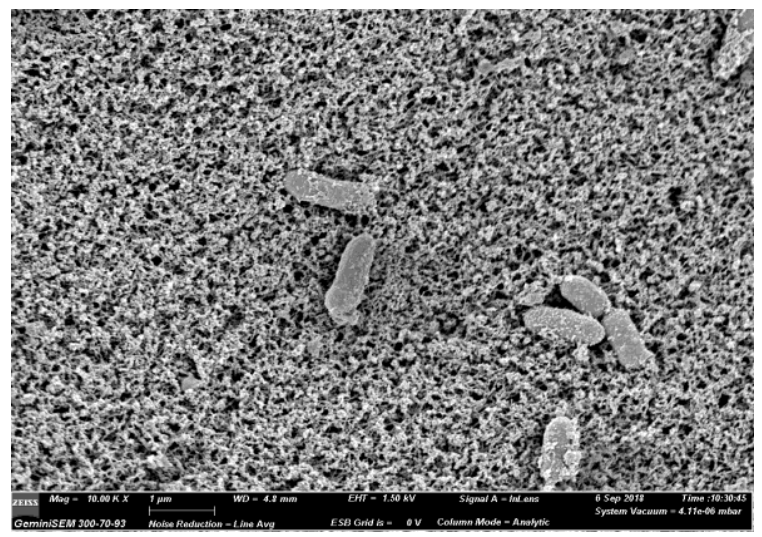

Fig. 2. Scanning electron micrograph (SEM) of South Shetland Trench strains, a) Dietzia maris SST1 at magnification $(\times 10,000)$, b) Pseudomonas zhaodongensis SST2 $(\times 10,280)$, c) Pseudomonas sp. SST3 $(\times$ 12,000), d) Halomonas sulfidaeris SST4 (× 10,000). 


\subsection{Biological Screening}

Biological screening results demonstrated that SST3 and SST4 have widespread antimicrobial and antifungal activities. Among tested strains, SST2 showed a promising antifungal activity against $A$. fumigatus ATCC46645. The SST1 strain was not tested for biological activity (Table 4). All strains exhibited no cytotoxicity in the MTT assay against Hep-G2 hepatic cell line.

Table 4. Inhibition of pathogens by SST (2-4) extracts.

\begin{tabular}{llll}
\hline Organism & SST2* & SST3* & SST4** \\
\hline E. coli ATCC29522 & -3 & 40 & -97 \\
A. baumannii MB5973 & 19 & 1 & -101 \\
MRSA MB5393 & -11 & 18 & -104 \\
C. albicans ATCC64124 & $-27 * * *$ & -3 & -62 \\
A. fumigatus ATCC46645**** & -109 & -60 & -64 \\
\hline
\end{tabular}

All values represent average inhibition from duplicate screenings. *Crude extract of SST2 and SST3. **Dichloromethane fraction of SST4. ***Values representing single data points. ****A. fumigatus ATCC46645 were not run in duplicate.

\subsection{Secondary Metabolism Biosynthetic Gene Clusters}

For biosynthetic gene clusters prediction, the whole genomes were mined using Antibiotic and Secondary Metabolites Analysis Shell "antiSMASH 4.1.1" and the data are presented in Table 5.

The analysis of the genomes of these isolates demonstrated a significant difference in their BGCs. Strain D. maris SST1 was found to contain 36 BGCs coding for ectoine (75\% genes similarity), carotenoid (100\% genes similarity), polyketide synthase (PKS), saccharides, fatty acids as well as putative clusters, in particular of novobiocin (20\% genes similarity) and griseobactin (11\% genes similarity) types. The Pseudomonas strains SST2 and SST3 exhibited some BGCs similarity reads for nonribosomal peptide synthetases (NRPs), bacteriocin, arylpolyene, fatty acids, saccharides as well as pyoverdines BGCs. Furthermore, an interesting xanthoferrin siderophore biosynthetic gene cluster was identified in SST3 strain with (100\% genes similarity). Finally, Halomonas sulfidaeris SST4 genome 
data reveals the presence of $30 \mathrm{BGCs}$ responsible for terpenes (carotenoid, 100\% genes similarity), ectoine ( $75 \%$ genes similarity), saccharides, fatty acids in addition to a hybrid lassopeptide-Cf saccharide and promising putative serobactins biosynthetic gene clusters (23\% genes similarity) were also identified (Fig. 3).

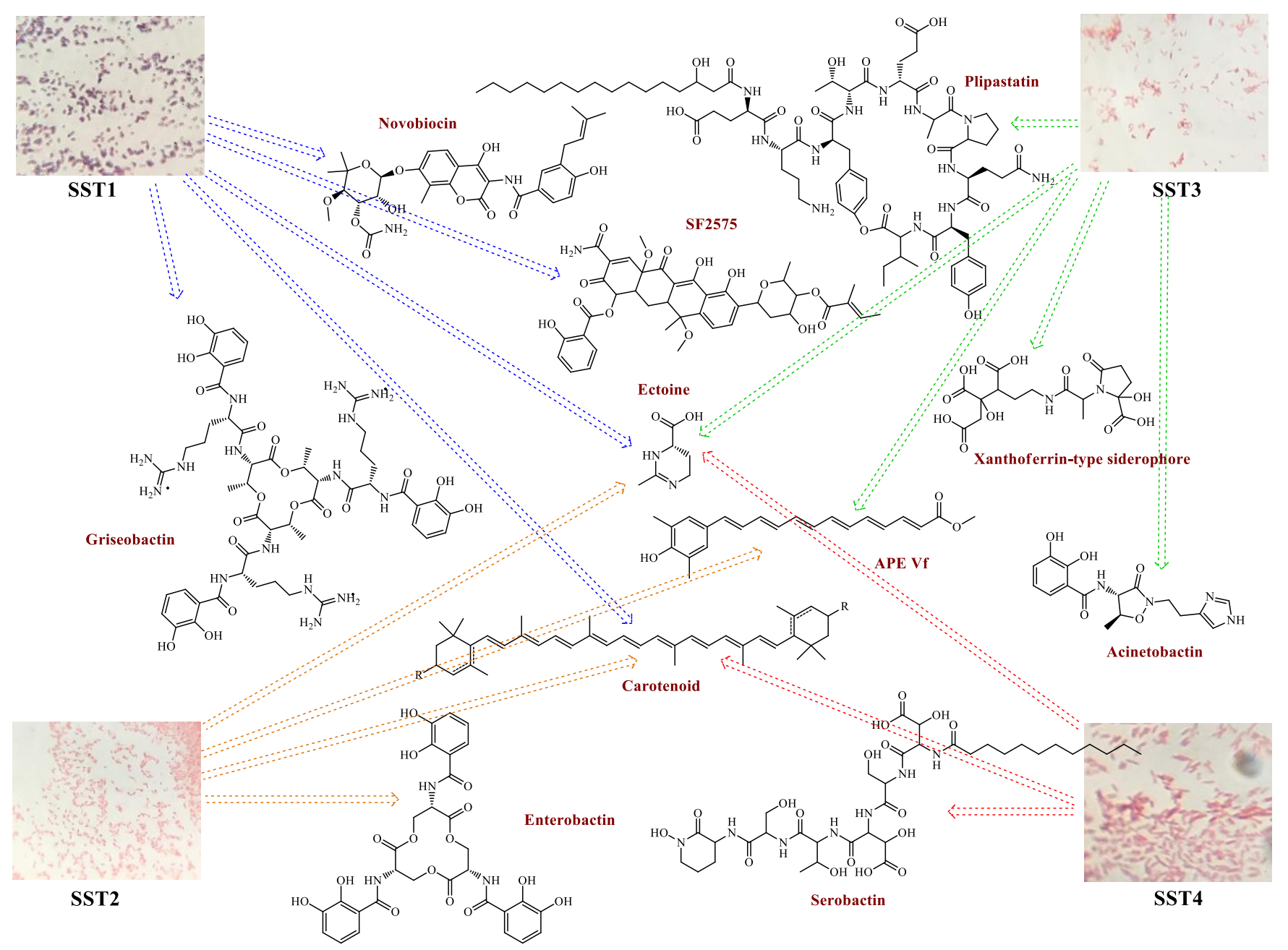

Fig. 3. The predicted secondary metabolites of SST species identified by genomic mining with antiSMASH 4.1.1. 
Table 5. The predicted secondary metabolite biosynthetic gene clusters (antiSMASH 4.1.1).

\begin{tabular}{|c|c|c|c|c|c|c|c|c|}
\hline \multirow{2}{*}{ BGCs } & \multicolumn{2}{|r|}{ SST1 } & \multicolumn{2}{|r|}{ SST2 } & \multicolumn{2}{|r|}{ SST3 } & \multicolumn{2}{|r|}{ SST4 } \\
\hline & No. & Type, (genes similarity) & No. & Type, (genes similarity) & No. & Type, (genes similarity) & No. & Type, (genes similarity) \\
\hline Ectoine & 1 & Ectoine BGC, (75\%) & 1 & Ectoine BGC, $(83 \%)$ & 1 & Ectoine BGC, $(66 \%)$ & 1 & Ectoine BGC, $(75 \%)$ \\
\hline Siderophore & - & - & - & - & 2 & $\begin{array}{l}\text { Including: } \\
\text { Xanthoferrin BGC, }(100 \%)\end{array}$ & - & - \\
\hline Bacteriocin & - & - & 1 & & 4 & & - & \\
\hline Terpene & 2 & $\begin{array}{l}\text { SF2575 BGC, }(6 \%) \\
\text { Carotenoid, }(100 \%)\end{array}$ & 1 & Carotenoid BGC, (100\%) & - & - & 1 & Carotenoid BGC, $(100 \%)$ \\
\hline T1PKS* & 1 & T1pks-Cf_saccharide & - & - & - & - & - & - \\
\hline T2PKS** & - & - & - & - & - & - & - & - \\
\hline T3PKS*** & - & - & - & - & - & - & 1 & \\
\hline NRPS**** & - & - & 1 & Enterobactin BGC, $(16 \%)$ & 2 & $\begin{array}{l}\text { Acinetobactin BGC, }(8 \%) \\
\text { Pyoverdine BGC, }(3 \%)\end{array}$ & - & - \\
\hline Cf saccharide & 2 & & 5 & $\begin{array}{l}\text { Including: } \\
\text { - Lipopolysaccharide BGC, }(27 \%) \\
\text { - Polysaccharide B BGC, }(10 \%) \\
\text { - O-antigen BGC, }(21 \%)\end{array}$ & 6 & $\begin{array}{l}\text { Including: } \\
\text { - Lipopolysaccharide BGC, }(36 \%) \\
\text { - Polysaccharide B BGC, }(10 \%) \\
\text { - O-antigen BGC, }(28 \%) \\
\text { - O-antigen BGC, }(64 \%)\end{array}$ & 3 & $\begin{array}{l}\text { Including: } \\
\text { - Polysaccharide B BGC, }(6 \%) \\
\text { - O\&K-antigen BGC, }(3 \%)\end{array}$ \\
\hline Cf fatty acid & 2 & & 3 & $\begin{array}{l}\text { Including: } \\
\text { Svaricin BGC, }(6 \%)\end{array}$ & 8 & $\begin{array}{l}\text { Including: } \\
\text { Svaricin BGC, (12\%) }\end{array}$ & 3 & $\begin{array}{l}\text { Including: } \\
\text { Svaricin BGC, (6\%) }\end{array}$ \\
\hline Arylpolyene & - & 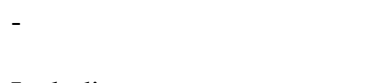 & 1 & APE Vf BGC, $(40 \%)$ & 3 & $\begin{array}{l}\text { Including: } \\
\text { APE Vf BGC, }(50 \%)\end{array}$ & - & 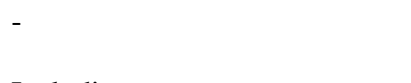 \\
\hline Cf putative & 28 & $\begin{array}{l}\text { Including: } \\
\text { - Griseobactin, BGC, }(11 \%) \\
\text { - Meilingmycin, BGC, }(2 \%) \\
\text { - A54145 BGC, }(3 \%) \\
\text { - Novobiocin BGC, }(20 \%) \\
\text { - Enduracidin BGC, }(4 \%) \\
\text { - Asukamycin BGC, }(3 \%)\end{array}$ & 14 & $\begin{array}{l}\text { Including: } \\
\text { - O-antigen BGC, (19\%) } \\
\text { - Lipopolysaccharide BGC, (5\%) }\end{array}$ & 29 & $\begin{array}{l}\text { Including: } \\
\text { - O-antigen BGC, }(21 \%) \\
\text { - Plipastatin BGC, }(15 \%) \\
\text { - Ustilagic acid BGC, }(1 \%) \\
\text { - Lipopolysaccharide BGC, }(16 \%)\end{array}$ & 19 & $\begin{array}{l}\text { Including: } \\
\text { - Serobactins BGC, }(23 \%) \\
\text { - Lipopolysaccharide BGC, } \\
(5 \%)\end{array}$ \\
\hline Lasso peptide & - & - & 1 & Pyoverdine BGC, $(4 \%)$ & 1 & Pyoverdine BGC, $(4 \%)$ & 1 & $\begin{array}{l}\text { Lasso peptide-Cf saccharide } \\
\text { BGC },(8 \%)\end{array}$ \\
\hline Hserlactone & - & - & - & - & 1 & & 1 & \\
\hline Other***** & - & - & - & - & 1 & & - & - \\
\hline Total & 36 & & 28 & & 58 & & 30 & \\
\hline
\end{tabular}

*Type I PKS cluster, **Type II PKS cluster, ***Type III PKS cluster, ****Nonribosomal peptide synthetase cluster, *****Cluster containing a secondary metabolite-related protein that does not fit into any other category. 


\subsection{Comparative metabolomics}

Molecular networking of mass spectrometric analyses of the four bacterial strains is visualized as one complete network, totaling 980 ions (nodes). Each colored node pertains to a specific SST strain, triangular nodes pertain to media components, and grey and circular nodes represent ions present in multiple bacterial metabolite profiles. Thirty five ions were dereplicated in the GNPS library with the DKPs being the most dereplicated class of specialized metabolite present in the analysis. The GNPS library also identified multiple lipopeptides, including (E) plipastatin, which is predicted by in silico genome analysis of SST3. Also identified is a group of surfactins (A-D), along with several other derivatives unidentified by dereplication (Fig. 4).

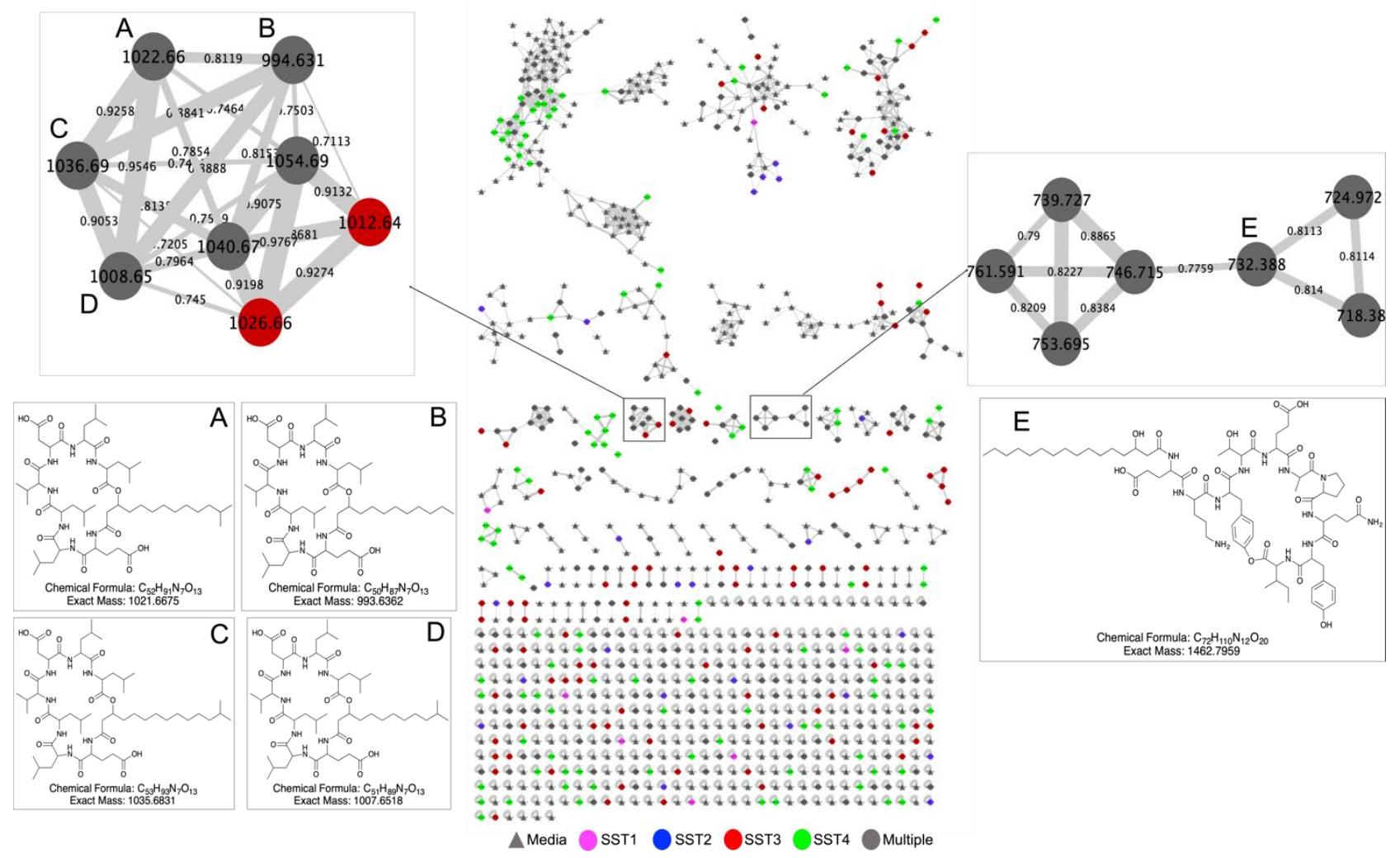

Fig. 4. Molecular network of 980 ions produced by SST bacteria. Node colors are based on bacterial strains. Gray, triangular nodes represent media components and gray, circular nodes represent ions found in multiple strains. Nodes represented in boxes display ions as the previously identified metabolites (A) surfactin C14 (B) surfactin derivative (C) surfactin C15 (D) surfactin C13 and (E) plipastatin. 
Out of the 980 ions present in the network, 440 (44.9\%) are ions produced by the strains (i.e. not media components). Hundred ninety nine ions (45.2\%) are attributed to more than one strain and SST3 and SST4 represent 208 ions (47.2\%). With this information, it is clear that SST3 and SST4 demonstrate great potential for new chemistry, coupled with bioactivity data, these two strains show great potential for further natural products discovery.

\subsection{Genomic insights into adaptation strategies}

The SST strains survive in a deep-sea environment, which is characterized by low temperatures and high pressures. Genomic insight into adaptation strategies in this environment was performed by exhaustive data mining of the genomes of these strains for the known stress associated genes using NCBI GenBank annotation pipeline and RAST tool. A detailed discussion of putative stress response related genes found in these isolates is provided below.

\subsubsection{Cold shock response}

Cold shock, as experienced in the deep sea, is a phenomenon that affects the growth of cell, membrane function and structure as well as the rates of protein synthesis, DNA and RNA translation. All SST strains have adapted to the temperature downshift via the production of cold-shock proteins Csps. The data mining across the SST genomes exhibited the occurrences of multiple copies of genes encoding for cold-shock inducible proteins, such as CspD, GroL, ClpB, GroES, FliJ/ Flis, SurA, SecB, HtpG and HscA/ HscB (Table S1). As previously reported in many other psychrotrophic bacteria, such as Pseudomonas fragi and Pseudomonas putida, the ability to produce a variety of cold shock inducible proteins is essential for the adaptation at low temperatures (Whyte et al., 1992; Michel et al., 1997). 


\subsubsection{Osmotic stress response}

Bacteria in the deep marine ecosystem are exposed to freezing conditions which greatly affect the extracellular environment leading to disturbance in the internal osmotic balance. The cells usually tend to readjust the balance in the internal osmotic pressure by accumulation of different compatible solutes, small organic molecules, which do not interfere with central metabolism, even if they accumulate to high concentrations by transport and/or biosynthesis. These compounds can be classified into different categories, such as ectoines (ectoine and hydroxyectoine) (Kuhlmann et al., 2011), sugars (glucans) (Lequette et al., 2008), peptides ( $N$-acetylglutaminylglutamine amide, NAGGN) (Sagot et al., 2010), as well as amino acids and their derivatives (choline and glycine betaine, sarcosine) (Table S1) (Landfald and Strøm, 1986; Fitzsimmons et al., 2012; García-Estepa et al., 2006).

The SST genomic mining revealed the presence of many genes associated with the synthesis and accumulation of such solutes, including: $E c t C, E h u A B$ for ectoine/hydroxyectoine biosynthesis, transportation and regulation system; $M d o G$ and $M d o H$ for periplasmic glucan biosynthesis; in addition to BetABT, ChoX, OpuAC for choline, betaine, glycine/betaine and glycine betaine/L-proline biosynthesis and regulation. The presence of these genes indicates the significance of compatible solutes as osmoregulators to counteract the osmotic stress at deep sea environments. Other predicted genes for osmoregulation are sarcosine oxidase Sox, outer membrane protein A precursor OmpA, osmotically inducible protein $O s m Y$, Aquaporin $\mathrm{Z}$ protein and osmoprotectant NAGGN $(N-$ acetylglutaminylglutamine amide) system M42 family peptidase that was discovered in many bacteria grown at high osmolarity such as Sinorhizobium meliloti (Gouffi and Blanco, 2000; Sagot et al., 2010)

\section{(Table S1).}




\subsubsection{Oxidative stress response}

Deep marine microorganisms are often exposed to reactive oxygen species (ROS) in low temperature environments. The exposure to this condition reduces the general enzymatic activities, thus lowering the ATP demand leading to the generation of ROS. In order to combat the damaging effects caused by the ROS, the deep marine bacteria must have antioxidant enzymes encoding genes to protect themselves from the drastic conditions, such as genes responsible for superoxide dismutase, several catalases, reductases, peroxidases, glutaredoxin, peroxiredoxin and thioredoxin which have been detected in many copies in the SST genomes and have the ability to repair the damage caused to proteins and other cell components by ROS (Table S2) (Goordial et al., 2016; Kumar et al., 2018). A number of such antioxidant-related genes were detected in many psychrophilic bacteria such as Rhodococcus and Alteromonas spp (Math et al., 2012; Goordial et al., 2016).

\subsubsection{Respiration}

The SST strains have many putative genes encoding terminal oxidases for aerobic respiration, such as cytochrome $d$ ubiquinol oxidases subunit I, II genes $C y d A B$, cytochrome $o$ ubiquinol oxidases $C y o A B C B$, generic cytochrome $c$ oxidase of $a a_{3}$-type, $c b b_{3}$-type cytochrome $c$ oxidase assembly protein CcoNOPQS, and cytochrome oxidase biogenesis protein FixG (Tables S2 and $\underline{\mathrm{S} 3}$ ). The cytochrome $d$ oxidase, $C y d$ and $c b b_{3}-c c o$ type oxidases complexes exhibit a high affinity for $\mathrm{O}_{2}$ allowing respiration under microaerobic conditions. Inversely, the $C y o$ and $a a_{3}$-type oxides complexes showed a low affinity for $\mathrm{O}_{2}$ and work only at high $\mathrm{O}_{2}$ tension (Aono et al., 2010).

Furthermore, the genome analyses of these isolates revealed the presence of genes encoding a number of terminal reductases and distinct dehydrogenases involved in the respiratory chains such as ferric reductase, ferredoxin reductase, arsenate reductase $\operatorname{Ars} C$, flavodoxin reductases (ferredoxin- 
NADPH reductases), polysulfide reductase and fumarate reductase $F r d A$, which can be used as terminal electron acceptors in anaerobic respiration condition. In addition, these bacteria have a potential to produce respiratory dehydrogenases (electron donating system) include NADH-quinone oxidoreductase (NADH dehydrogenase-1) Nuo, glycerol-3-phosphate dehydrogenase, L-lactate dehydrogenase in addition to several types of succinate and formate dehydrogenases (Table S3) (Unden and Bongaerts, 1997).

\subsubsection{Cell wall/membrane alteration}

One of the most crucial needs for organisms living in cold environments is the maintaining the cell membrane in the liquid crystalline state. Studies established that the psychrophilic bacteria maintain the functionality of the cell membrane by increasing the synthesis of lower-melting point branched-chain and/or polyunsaturated fatty acids (PUFAs) such as eicosapentaenoic acid (EPA) and docosahexaenoic acid (DHA), and phospholipids (Chattopadhyay and Jagannadham, 2003). The genomes analyses of SST strains revealed the presence of genes responsible for the synthesis of branched-chain and/or long chain polyunsaturated fatty acids such as 3-oxoacyl-ACP synthase, 3-oxoacyl-ACP reductase, ketoacyl-ACP synthase, beta-ketoacyl-ACP synthase III (FabH), enoyl-ACP reductase and long-chain fatty acid-CoA ligase, sterol/fatty acid desaturase as well as phytoene synthase/desaturase for carotenoid production (Table S4), which are linked to membrane fluidity at low temperature and resistance to freeze-thaw cycles that essential for cell viability at low temperatures (Choi et al., 2000; Chattopadhyay and Jagannadham, 2001; Okuyama et al., 2007; Dieser et al., 2010). It is worthy to say that PUFAs synthesis is also essential for growth of bacteria at high pressure as observed in Shewanella spp., Moriella marina and Colwellia psychrerythraea bacterial strains (Nichols et al., 1997; Fang et al., 2003; Ivanova et al., 2004; Methé et al., 2005; Usui et al., 2012; Kautharapu and Jarboe, 2012). 
The genome analysis of SST species revealed also the presence of two phospholipids biosynthesisrelated genes encoding cardiolipin synthetase $C l s$ and phosphatidylserine decarboxylase Psd (Table S4). The $c l s$ and $p s d$ genes play important roles for the bacterial adaptation in deep-sea environment (Yano et al., 1998; Pfeiffer et al., 2003; Kawamoto et al., 2009; Cao et al., 2019).

\subsubsection{Carbon starvation and storage}

The nutrient-limiting condition is one of the characters of the glacier and deep-sea ecosystems and the organisms must have genetic ability to store carbon in order to survive under these stress conditions. The genome analyses of SST species revealed the presence of genes encoding carbon storage regulator $C s r A$, stringent starvation protein A $(S s p A)$, and carbon starvation protein A $(C s t A)$, in addition to glycogen debranching enzyme $G \lg X$ and glycogen phosphorylase, which responsible for the breakdown of this storage molecule (Goordial et al., 2016). The genomes also showed multiple copies of PlsY gene encoding glycerol-3-phosphate acyltransferase which catalyze the synthesis of energy reserve triacylglycerol and phospholipid molecules (Olukoshi and Packter, 1994; Gao et al., 2013) in addition to carbonate dehydratase and carbonic anhydrase proteins that essential for efficient $\mathrm{CO}_{2}$ fixation (Table S5) (Cannon et al., 2010).

\subsubsection{Nitrogen metabolism}

With increased depth in the ocean, the level of organic nitrogen in deep-sea habitats is decreased (Schneider et al., 2003). The SST strains encoded the allantoin utilization genes (allB and puuE) as well as cyanase $(C y n S)$ and carbonic anhydrase $(C y n T)$ genes which are often clustered together for utilization of cyanate as source of nitrogen (Table S6) (Piedras et al., 1998). In addition, the SST genomes contain the genes encoding enzymes responsible for assimilation of inorganic nitrogen, nitrite 
and nitrate, such as NADH-dependent nitrite reductase (nirD), nitrate reductase (narGHIJ) and periplasmic nitrate reductase (napAE), that are present in favorable concentration in the upper layers of deep-sea sediments to produce ammonium which is the favored source of nitrogen for the bacteria, besides their using of any traces of organic nitrogen in order to maintain their growth in the deep marine habitats (Reitzer, 2003; Brunnegard et al., 2004; Muro-Pastor et al., 2005) (Fig. S1).

\subsubsection{Remineralization of organic matter}

The deep-sea organisms generally depend on the food coming through the global thermohaline circulation from primary production sources in the euphotic zone. The bacteria at the surface of the deep-sea sediments respond quickly to the arrival of any organic nutrients to the deep-sea floor, and begin to secrete the enzymes responsible for the degradation of complex organic compounds converting them into simple molecules, which can be easily metabolized by the bacteria. This process is critical for the remineralization of organic matter. The analysis of SST genomes allowed the identification of many genes encoding extracellular enzymes capable of hydrolyzing organic matter, such as polysaccharases and proteases with diverse substrates (Table S7). The results suggest a diversity of the extracellular enzymes secreted by SST species indicating that these bacteria can effectively feed on various types of organic matter that usually derived from various living or dead creatures as phytoplankton and in the short supply on the deep-sea floor (Piontek et al., 2011). The production of different types of hydrolyzing enzymes ensures that SST flourishes in an organic limiting deep-sea environment.

From the above detailed analysis, it is clear that SST species have a genetic potential to follow different strategies of deep sea environment adaptation which may explain their ability to live in these extreme environments. The SST species encoded genes for the production of a variety of cold-shock 
inducible proteins that are essential for adaptation to low temperatures. It is worth mentioning that this single environmental stress may simultaneously initiate multiple stress responses at the intracellular level. Cold stress under freezing conditions, accompanied with other abiotic stress types, is known to disturb the internal osmotic balance and induce the production of reactive oxygen species (ROS). To overcome the osmotic stress response, the SST strains explore the genes responsible for accumulation of different compatible solutes and small organic molecules, such as ectoines, sugars, amino acids and peptides. These solutes also play roles in protecting cells from reactive oxygen radicals beside their protection effect from osmotic pressure and cold stress. As cold stress can induce the ROS, which can disturb the cellular redox homeostasis leading to oxidative damage to nucleic acids, membrane lipids and proteins, the SST strains have genes responsible for the production of such antioxidant enzymes as superoxide dismutase, catalase, glutathione peroxidase, which repair and protect cell components from the damage caused by ROS.

In the deep-sea floor, the oxygen concentration is low in spite of the global thermohaline circulations which supply the deep sea floor with the dissolved oxygen. Thus, the SST species possess many cytochrome oxidase complexes of different affinities for oxygen as well as a number of terminal reductases and distinct dehydrogenases implying that SST species have undergone respiratory adaptation either to oxic conditions in the upper layers of sediments or anoxic conditions in the lower layers. Moreover, the analysis of the SST genomes revealed the presence of the genes responsible for the synthesis of PUFAs and/or branched chain fatty acids, as well as phospholipids to maintain the cell membrane in the liquid crystalline state (homeoviscous adaptation), which is considered important for the organisms living in cold environments.

Due to deficiency of nutrients in deep sea environment, the SST strains harbor many genes encoding extracellular enzymes capable of hydrolyzing organic matter, such as polysaccharases and proteases in 
addition to their genetic capacity to acquire and store carbon. They tend to break down the carbon storage molecules such as glycogen for obtaining carbon in addition to their ability for $\mathrm{CO}_{2}$ fixation. The genome analyses of SST species also exhibited the presence of genes encoding carbon storage regulator CsrA, stringent starvation protein A (SspA), and carbon starvation protein A (CstA). Access of SST strains to nitrogen is assisted by cyanate utilization genes cynS and cynT, as well as by allantoin utilization genes allB and puuE. The SST strains also tend to use external nitrate and nitrite present in higher concentrations in the upper layers of deep-sea sediments to produce ammonium which is the favored source of nitrogen for the bacteria.

\section{Conclusions}

The whole genome analyses of the SST species elicited the presence of BGCs responsible for production of different classes of compounds such as terpenoids, peptides, arylpolyenes, and siderophores. The most exciting finding is the presence of an interesting xanthoferrin siderophore BGC in SST3, arylpolyene BGCs in SST2 and SST3, and a promising serobactins BGC in SST4 as well as novobiocin BGC in SST1. Many BGCs were identified responsible for production of different classes of peptides, such as plipastatin, a lipopeptide antibiotic, in SST3; giseobactin, a catechol-peptide siderophore, in SST1; and lasso peptides in SST2, SST3 and SST4. The comparative metabolomics by molecular networking using Global Natural Product Social (GNPS) Molecular Networking confirmed the presence of multiple lipoptides in the SST extracts, including plipastatin and surfactins which possess promising antibiotic activity (Volpon et al., 2000; Meena and Kanwar, 2015; Kluge et al., 1988). The comparative metabolomics analysis also revealed the high affinity of both SST3 and SST4 bacterial strains for new chemistry production, coupled with bioactivity data, indicating these two strains show great potential for further natural products discovery. Bioassay-guided isolation of the bioactive natural 
products is planned guided by the genomic information and findings from this study. The OSMAC approach (Bode et al., 2002) will now be applied to the four new strains in order to evaluate the most interesting chemistry and biology.

Furthermore, comparative genome analyses of the SST strains also revealed the genes involved in adaptation of these bacteria to environmental conditions at the surface layer of deep-sea sediments, allowing them to withstand anoxic, low temperature and high pressure stress conditions. This study suggests that these bacteria are capable of acquiring and storing carbon as well as utilizing different sources of nitrogen, such as nitrates, nitrites, cyanates and allantoin. In addition, these bacteria contain fatty acid and phospholipid related genes responsible for adaptation to extreme environments. The data also indicate the importance of the global thermohaline circulation for maintaining a steady supply of oxygen and organic matter.

\section{Funding}

This research was funded by the Deanship of Scientific Research at Princess Nourah bint Abdulrahman University through the Fast-track Research Funding Program.

\section{Acknowledgments}

L.H.A. thanks the Deanship of Scientific Research at Princess Nourah bint Abdulrahman University for funding this work through the Fast-track Research Funding Program. The authors thank the Captain, crew and scientific party of the 2015-16 'PharmaDeep' cruise on the Spanish Antarctic vessel BIO Hesperides. The cruise activity was supported by the European Union Research Infrastructures project 'EuroFleets $2^{\prime}$ under the $7^{\text {th }}$ Framework Programme of the European Commission (agreement no. 312762). A.J.J. was the awardee of PharmaDeep: New Pharmaceuticals from the deep Antarctic. The 
authors also would like to thank John Still at ACEMAC for SEM images and the assay providers at Medina for their contribution.

\section{Author contributions}

Conceptualization: Wael M. Abdel-Mageed, Scott A. Jarmusch, Andrey V. Karlyshev, Marcel Jaspars.

Methodology: Wael M. Abdel-Mageed, Burhan Lehri, Scott A. Jarmusch, Kevin Miranda.

Formal analysis: Wael M. Abdel-Mageed, Burhan Lehri, Scott A. Jarmusch, Lamya H. Al-Wahaibi.

Investigation: Wael M. Abdel-Mageed, Burhan Lehri, Scott A. Jarmusch, Kevin Miranda, Andrey V. Karlyshev, Marcel Jaspars.

Resources: Alan J. Jamieson, Heather A. Stewart, Marcel Jaspars.

Data curation: Wael M. Abdel-Mageed, Burhan Lehri, Scott A. Jarmusch.

Funding acquisition: Lamya $\mathrm{H}$. Al-Wahaibi

Project administration: Wael M. Abdel-Mageed, Andrey V. Karlyshev, Marcel Jaspars.

Supervision: Andrey V. Karlyshev, Marcel Jaspars

Writing - Original Draft: Wael M. Abdel-Mageed, Burhan Lehri, Scott A. Jarmusch, Kevin Miranda, Lamya H. Al-Wahaibi

Writing, review \& editing: All authors. 


\section{References}

Abdel-Mageed, W.M., Milne, B.F., Wagner, M., Schumacher, M., Sandor, P., Pathom-aree, W., Goodfellow, M., Bull, A.T., Horikoshi, K., Ebel, R., Diederich, M., Fiedler, H.P., Jaspars, M., 2010. Dermacozines, a new phenazine family from deep-sea dermacocci isolated from a Mariana Trench sediment. Org. Biomol. Chem. 8, 2352-2362.

Altschul, S.F., Gish, W., Miller, W., Myers, E.W., Lipman, D.J., 1990. Basic local alignment search tool. J. Mol. Biol. 215, 403-410.

Aono, E., Baba, T., Ara, T., Nishi, T., Nakamichi, T., Inamoto, E, et al., 2010. Complete genome sequence and comparative analysis of Shewanella violacea, a psychrophilic and piezophilic bacterium from deep sea floor sediments. Mol. Biosyst. 6, 1216-1226.

Aziz, R.K., Bartels, D., Best, A.A., DeJongh, M., Disz, T., Edwards, R.A., et al., 2008. The RAST server: rapid annotations using subsystems technology. BMC Genomics. 9, 75-89.

Bode, H.B., Bethe, B., Höfs, R., Zeeck, A., 2002. Big effects from small changes: possible ways to explore nature's chemical diversity. ChemBioChem. 3, 619-627.

Brunnegard, J., Grandel, S., Stahl, H., Tengberg, A., Hall, P.O.J., 2004. Nitrogen cycling in deep-sea sediments of the Porcupine Abyssal Plain, NE Atlantic. Prog. Oceanogr. 63, 159-181.

Cannon, G.C., Heinhorst, S., Kerfeld, C.A., 2010. Carboxysomal carbonic anhydrases: Structure and role in microbial $\mathrm{CO}_{2}$ fixation. Biochim. Biophys. Acta. 1804, 382-392.

Cao, J., Liu, P., Liu, R., Su, H., Wei, Y., Liu, R., Fang, J., 2019. Marinobacter profundi sp. nov., a slightly halophilic bacterium isolated from a deep-sea sediment sample of the New Britain Trench. Antonie Van Leeuwenhoek 112, 425-434. 
Cautain, B., de Pedro, N., Schulz, C., Pascual, J., Sousa Tda, S., Martin, J., et al., 2015. Identification of the Lipodepsipeptide MDN-0066, a Novel Inhibitor of VHL/HIF Pathway Produced by a New Pseudomonas Species. PLoS One. 10, e0125221.

Chattopadhyay, M., Jagannadham, M., 2001. Maintenance of membrane fluidity in Antarctic bacteria. Polar Biol. 24, 386-388.

Chattopadhyay, M.K., Jagannadham, M.V., 2003. A branched chain fatty acid promotes cold adaptation in bacteria. J. Biosci. 28, 363-364.

Choi, K.H., Heath, R.J., Rock, C.O., 2000. beta-ketoacyl-acyl carrier protein synthase III (FabH) is a determining factor in branched-chain fatty acid biosynthesis. J. Bacteriol. 182, 365-370.

Dieser, M., Greenwood, M., Foreman, C.M., 2010. Carotenoid pigmentation in Antarctic heterotrophic bacteria as a strategy to withstand environmental stresses. Arct. Antarct. Alp. Res. 42, 396-406.

Donald, B., Bryan, M., Christopher, W., Kyle, S., Richard, R., 2013. Colony Morphology Protocol. American Society for Microbiology, USA.

Fang, J., Chan, O., Kato, C., Sato, T., Peeples, T., Niggemeyer, K., 2003. Phospholipid FA of piezophilic bacteria from the deep sea. Lipids $38,885-887$.

Felsenstein, J., 1985. Confidence limits on phylogenies: An approach using the bootstrap. Evolution 39, 783-791.

Fitzsimmons, L.F., Hampel, K.J., Wargo, M.J., 2012. Cellular choline and glycine betaine pools impact osmoprotection and phospholipase C production in Pseudomonas aeruginosa. J. Bacteriol. 194, $4718-4726$.

Gao, Q., Shang, Y., Huang, W., Wang, C., 2013. Glycerol-3-phosphate Acyltransferase contributes to triacylglycerol biosynthesis, lipid droplet formation, and host invasion in Metarhizium robertsii. Appl. Environ. Microbiol. 79, 7646-7653. 
García-Estepa, R., Argandoña, M., Reina-Bueno, M., Capote, N., Iglesias-Guerra, F., Nieto, J.J., Vargas, C., 2006. The ectD gene, which is involved in the synthesis of the compatible solute hydroxyectoine, is essential for thermoprotection of the halophilic bacterium Chromohalobacter salexigens. J. Bacteriol. 188, 3774-3784.

Goordial, J., Raymond-Bouchard, I., Zolotarov, Y., de Bethencourt, L., Ronholm, J., Shapiro, N., et al., 2016. Cold adaptive traits revealed by comparative genomic analysis of the eurypsychrophile Rhodococcus sp. JG3 isolated from high elevation McMurdo Dry Valley permafrost, Antarctica. FEMS Microbiol. Ecol. 92, pii: fiv154.

Gouffi, K., Blanco, C., 2000. Is the accumulation of osmoprotectant the unique mechanism involved in bacterial osmoprotection?. Int. J. Food Microbiol. 55, 171-174.

Ivanova, E.P., Gorshkova, N.M., Bowman, J.P., Lysenko, A.M., Zhukova, N.V., Sergeev, A.F., Mikhailov, V.V., Nicolau, D.V., 2004. Shewanella pacifica sp. nov., a polyunsaturated fatty acidproducing bacterium isolated from sea water. Int. J. Syst. Evol. Microbiol. 54, 1083-1087.

Letunic, I., Bork, P., 2019. Interactive Tree Of Life (iTOL) v4: recent updates and new developments. Nucleic Acids Res. 47, W256-W259.

Jin, Y.K., Lee, J., Hong, J.K., Nam, S.H., 2009. Is subduction ongoing in the South Shetland Trench, Antarctic Peninsula?: new constraints from crustal structures of outer trench wall. Geosci. J. 13, 5967.

Kamjam, M., Sivalingam, P., Deng, Z., Hong, K., 2017. Deep Sea Actinomycetes and Their Secondary Metabolites. Front. Microbiol. 8, 760-768.

Kautharapu, K.B., Jarboe, L.R., 2012. Genome sequence of the psychrophilic deep-sea bacterium Moritella marina MP-1 (ATCC 15381). J. Bacteriol. 194, 6296-6297. 
Kawamoto, J., Kurihara, T., Yamamoto, K., Nagayasu, M., Tani, Y., Mihara, H., Hosokawa, M., Baba, T., Sato, S.B., Esaki, N., 2009. Eicosapentaenoic acid plays a beneficial role in membrane organization and cell division of a cold-adapted bacterium, Shewanella livingstonensis Ac10. J. Bacteriol. 191, 632-640.

Kluge, B., Vater, J., Salnikow, J., Eckart, K., 1988. Studies on the biosynthesis of surfactin, a lipopeptide antibiotic from Bacillus subtilis ATCC 21332. FEBS Lett. 231, 107-110.

Kuhlmann, A.U., Hoffmann, T., Bursy, J., Jebbar, M., Bremer, E., 2011. Ectoine and hydroxyectoine as protectants against osmotic and cold stress: uptake through the SigB-controlled betaine-cholinecarnitine transporter-type carrier EctT from Virgibacillus pantothenticus. J. Bacteriol. 193, 46994708.

Kumar, R., Acharya, V., Mukhia, S., Singh, D., Kumar, S., 2018. Complete genome sequence of Pseudomonas frederiksbergensis ERDD5:01 revealed genetic bases for survivability at high altitude ecosystem and bioprospection potential. Genomics pii: S0888-7543, 30152-30156.

Kumar, S., Stecher, G., Tamura, K., 2016. MEGA7: Molecular Evolutionary Genetics Analysis version 7.0 for bigger datasets. Mol. Biol. Evol. 33, 1870-1874.

Kupchan, S.M., Britton, R.W., Ziegler, M.F., Sigel, C.W., 1973. Bruceantin, a new potent antileukemic simaroubolide from Brucea anti- dysenterica. J. Org. Chem. 38, 178-179.

Landfald, B., Strøm, A.R., 1986. Choline-glycine betaine pathway confers a high level of osmotic tolerance in Escherichia coli. J. Bacteriol. 165, 849-855.

Lequette, Y., Lanfroy, E., Cogez, V., Bohin, J.P., Lacroix, J.M., 2008. Biosynthesis of osmoregulated periplasmic glucans in Escherichia coli: the membrane-bound and the soluble periplasmic phosphoglycerol transferases are encoded by the same gene. Microbiology 154, 476-483. 
Math, R.K., Jin, H.M., Kim, J.M., Hahn, Y., Park, W., Madsen, E.L., Jeon, C.O., 2012. Comparative genomics reveals adaptation by Alteromonas sp. SN2 to marine tidal-flat conditions: cold tolerance and aromatic hydrocarbon metabolism. PLoS One. 7, e35784.

Meena, K.R., Kanwar, S.S., 2015. Lipopeptides as the antifungal and antibacterial agents: applications in food safety and therapeutics. Biomed. Res. Int. 2015, 473050.

Methé, B.A., Nelson, K.E., Deming, J.W., Momen, B., Melamud, E., Zhang, X., et al., 2005. The psychrophilic lifestyle as revealed by the genome sequence of Colwellia psychrerythraea $34 \mathrm{H}$ through genomic and proteomic analyses. Proc. Natl. Acad. Sci. U S A 102, 10913-10918.

Michel, V., Lehoux, I., Depret, G., Anglade, P., Labadie, J., Hebraud, M., 1997. The cold shock response of the psychrotrophic bacterium Pseudomonas fragi involves four low-molecular-mass nucleic acid-binding proteins. J. Bacteriol. 179, 7331-7342.

Muro-Pastor, M.I., Reyes, J.C., Florencio, F.J., 2005. Ammonium assimilation in cyanobacteria. Photosynth. Res. 83, 135-150.

Nichols, D.S., Nichols, P.D., Russell, N.J., Davies, N.W., McMeekin, T.A., 1997. Polyunsaturated fatty acids in the psychrophilic bacterium Shewanella gelidimarina ACAM 456T: molecular species analysis of major phospholipids and biosynthesis of eicosapentaenoic acid. Biochim. Biophys. Acta. $1347,164-176$.

Okuyama, H., Orikasa, Y., Nishida, T., Watanabe, K., Morita, N., 2007. Bacterial genes responsible for the biosynthesis of eicosapentaenoic and docosahexaenoic acids and their heterologous expression. Appl. Environ. Microbiol. 73, 665-670.

Olukoshi, E.R., Packter, N.M., 1994. Importance of stored triacylglycerols in Streptomyces: possible carbon source for antibiotics. Microbiology 140, 931-943. 
Pfeiffer, K., Gohil, V., Stuart, R.A., Hunte, C., Brandt, U., Greenberg, M.L., Schägger, H., 2003. Cardiolipin stabilizes respiratory chain supercomplexes. J. Biol. Chem. 278, 52873-52880.

Piedras, P., Aguilar, M., Pineda, M., 1998. Uptake and metabolism of allantoin and allantoate by cells of Chlamydomonas reinhardtii (Chlorophyceae). Eur. J. Phycol. 33, 57-64.

Piontek, J., Händel, N., De Bodt, C., Harlay, J., Chou, L., Engel, A., 2011. The utilization of polysaccharides by heterotrophic bacterioplankton in the Bay of Biscay (North Atlantic Ocean). J. Plankton Res. 33, 1719-1735.

Reitzer, L., 2003. Nitrogen assimilation and global regulation in Escherichia coli. Annu. Rev. Microbiol. 57, 155-176.

Sagot, B., Gaysinski, M., Mehiri, M., Guigonis, J.M., Le Rudulier, D., Alloing, G., 2010. Osmotically induced synthesis of the dipeptide $N$-acetylglutaminylglutamine amide is mediated by a new pathway conserved among bacteria. Proc. Natl. Acad. Sci. U S A 107, 12652-12657.

Schneider, B., Schlitzer, R., Fischer, G., Nothig, E.-M., 2003. Depth-dependent elemental compositions of particulate organic matter (POM) in the ocean. Global Biogeochem. Cycles 17, 1032-1047.

Skropeta, D., 2008. Deep-sea natural products. Nat. Prod. Rep. 25, 1131-1166.

Skropeta, D., Wei, L., 2014. Recent advances in deep-sea natural products. Nat. Prod. Rep. 31, 9991025.

Tamura, K., Nei, M., 1993. Estimation of the number of nucleotide substitutions in the control region of mitochondrial DNA in humans and chimpanzees. Mol. Biol. Evol. 10, 512-526.

Unden, G., Bongaerts, J., 1997. Alternative respiratory pathways of Escherichia coli: energetics and transcriptional regulation in response to electron acceptors. Biochim. Biophys. Acta. 1320, 217-234.

Usui, K., Hiraki, T., Kawamoto, J., Kurihara, T., Nogi, Y., Kato, C., Abe, F., 2012. Eicosapentaenoic acid plays a role in stabilizing dynamic membrane structure in the deep-sea piezophile Shewanella 
violacea: a study employing high-pressure time-resolved fluorescence anisotropy measurement. Biochim. Biophys. Acta. 1818, 574-583.

Volpon, L., Besson, F., Lancelin, J.M., 2000. NMR structure of antibiotics plipastatins A and B from Bacillus subtilis inhibitors of phospholipase A(2). FEBS Lett. 485, 76-80.

Wagner, M., Abdel-Mageed, W.M., Ebel, R., Bull, A.T., Goodfellow, M., Fiedler, H.-P., Jaspars, M., 2014. Dermacozines H-J Isolated from a Deep-Sea Strain of Dermacoccus abyssi from Mariana Trench Sediments. J. Nat. Prod. 77, 416-420.

Wang, M., Carver, J.J., Phelan, V.V., Sanchez, L.M., Garg, N., Peng, Y., et al., 2016. Sharing and community curation of mass spectrometry data with Global Natural Products Social Molecular Networking. Nat. Biotechnol. 34, 828-837.

Weber, T., Blin, K., Duddela, S., Krug, D., Kim, H.U., Bruccoleri, R., et al., 2015. antiSMASH 3.0-a comprehensive resource for the genome mining of biosynthetic gene clusters. Nucleic Acids Res. 43(W1), W237-243.

Whyte, L.G., Inniss, W.E., 1992. Cold shock proteins and cold acclimation proteins in a psychrotrophic bacterium. Can. J. Microbiol. 38, 1281-1285.

Yano, Y., Nakayama, A., Ishihara, K., Saito, H., 1998. Adaptive changes in membrane lipids of barophilic bacteria in response to changes in growth pressure. Appl. Environ. Microbiol. 64, 479485 .

Yoon, S.H., Ha, S.M., Kwon, S., Lim, J., Kim, Y., Seo, H., Chun, J., 2017. Introducing EzBioCloud: A taxonomically united database of $16 \mathrm{~S}$ rRNA and whole genome assemblies. Int. J. Syst. Evol. Microbiol. 67, 1613-1617. 